\title{
Nuevas aportaciones a la historia constructiva de la escalera del Hospital de Santa Cruz en Toledo
}

\author{
Jorge MARTÍNEZ MONTERO \\ Escuela de Arte y Superior de Conservación \\ y Restauración de B.B.C.C. de León
}

Recibido: 15-5-2013 / Aceptado: 27-6-2013

RESUMEN: El desarrollo evolutivo de la escalera en la arquitectura asistencial española del siglo XVI tiene como principal referente a la implantación de la tipología claustral de tres tramos y caja abierta por parte de los maestros Enrique Egas y Alonso de Covarrubias en el Hospital toledano de Santa Cruz. En el análisis que proponemos establecemos nuevas hipótesis acerca de la autoría y materialización de la escalera, dilatándose en el tiempo más de una década y acercándose a su análoga, la escalera del Palacio Arzobispal de Alcalá de Henares.

Palabras clave: arquitectura civil, hospital, escalera, Renacimiento, Alonso de Covarrubias, Enrique Egas, Toledo, España, siglo XVI.

ABSTRACT: The evolutionary development of the staircase in the architecture of the sixteenth century Spanish healthcare has as main reference to the implementation of the type of staircase cloister of three flights and open flight by the master builders such as Enrique Egas and Alonso de Covarrubias in the Holy Cross Hospital in Toledo. In the analysis we propose establish new hypotheses concerning the authorship and realization of the staircase, dilating in time more than a decade and approaching its analogue, the staircase of Archbishop's Palace in Alcalá de Henares.

Key words: civil architecture, hospital, staircase, Renaissance, Alonso de Covarrubias, Enrique Egas, Toledo, Spain, 16th century.

"Si todavía las escaleras de la Universidad de Salamanca o las de San Juan de los Reyes de Toledo, pese a su monumentalidad, no son visibles desde el patio a causa de estar ubicadas en un ángulo como escondidas, en cambio existe toda una serie muy vistosa de las que la del Hospital de Santa Cruz de Toledo es el mejor ejemplo".

Antonio Bonet Correa, $1975^{1}$.

\footnotetext{
${ }^{1}$ A. BONET CORREA, "Introducción a las escaleras imperiales españolas", Cuadernos de Arte de la Universidad de Granada, XII, 24, 1975, p. 84.
} 


\section{LA ESCALERA EN LA ARQUITECTURA ASISTENCIAL ESPAÑOLA DEL SIGLO XVI}

Al amparo de la nueva conciencia social imperante en los inicios de la Edad Moderna, surgirá un nuevo concepto de beneficencia que nada tiene que ver con la atención caritativa medieval prestada al peregrino en albergues a lo largo del Camino de Santia$\mathrm{go}^{2}$. Antiguas leproserías, casas de expósitos o residencias de acogida entre otras, pasarán a unificarse en favor de la construcción de edificios exprofeso para tales fines.

El punto de partida de la génesis y evolución hospitalaria del Renacimiento español, lo encontramos durante el reinado de los Reyes Católicos (1474-1516), considerados auténticos benefactores de la asistencia a enfermos y necesitados, llevan a cabo la fundación de hospitales reales en dos centros, religiosa y simbólicamente significativos: las ciudades de Santiago de Compostela y Granada ${ }^{3}$. Este tipo de obras de patrocinio regio contaban con el beneplácito y apoyo de la corona, presente en el impulso constructivo y en la buena marcha de las mismas, en contraposición con la proliferación de obras hospitalarias bajo apoyos particulares de personajes eclesiásticos, de la alta nobleza, hermandades y cofradías, que luchaban por subsistir en un clima de cierta inestabilidad política ${ }^{4}$.

${ }^{2}$ D. LEISTIKOW, Edificios hospitalarios en Europa durante diez siglos. Historia de la arquitectura hospitalaria, C.H. Boehringer Sohn, 1967.

${ }^{3}$ R. DÍEZ DEL CORRAL GARNICA; F. CHECA CREMADES, "Typologie hospitaliere et bienfaisance dans l'Espagne de la Renaissance", Gazette des BeauxArts, CVII, 1986, pp. 118-126.

${ }^{4}$ R. DÍEZ DEL CORRAL GARNICA; F. CHECA CREMADES, “El Hospital Real de Granada y el Hospital de Santiago en Úbeda como ejemplos de la tipología hospitalaria en la España del siglo XVI", III Congreso Español de Historia del Arte, Sevilla, 1980, pp. 19-21; R. DÍEZ DEL CORRAL GARNICA, “La política hospitalaria en la España del siglo XVI: los hospitales toledanos", Arquitectura y mecenazgo. La imagen de Toledo en el Renacimiento, Madrid, 1987, pp. 177-185; F. MARÍAS FRANCO, "Arquitectura y sistema hospitalario en Toledo en el siglo XVI", Actes du colloque organisé par la
Tipológicamente, acorde a la nueva practicidad organizativa e higienista, surgirán diferentes modelos dispositivos en planta, entre los que Lampérez y Romea distingue de manera generalizada tres: basilical, cruciforme y palaciano ${ }^{5}$. Siendo el segundo de estos tipos, el cruciforme, el que mayor éxito obtuvo en la arquitectura asistencial de principios del siglo XVI, materializándose en la construcción de los Hospitales Generales de Santiago de Compostela (1501-1511), Zaragoza (1508), Granada (1511), Valencia (1512) y Toledo (1504-1515)

Procedente, según la historiografía tradicional, del modelo que Antonio Averlino el Filarete toma para la construcción del Hospital Mayor de Milán (1456-1465) o en opiniones más recientes, del Hospital del Santo Spiritu de Sassia en Roma (1474$1482)^{8}$, en el caso hispano, el programa hospitalario se desarrollará, disponiéndose de manera racional en torno a dos núcleos simétricos, formando una cruz griega en la que se disponen dos enormes patios, uno a cada lado de la capilla9.

Junta de Comunidades de Castilla-La Mancha et la Casa de Velázquez. Tolède et l'expansion urbaine en Espagne, 14501650, Toledo-Madrid, 1988. Madrid, 1991, pp. 49-68; C. SÁNCHEZ-ROBLES BELTRÁN, “El programa: el alojamiento colectivo y transitorio. El hospital general: $\mathrm{S}$. XV y XVI", Revisiones, Valencia, 1997, pp. 173-260.

${ }^{5}$ V. LAMPÉREZ Y ROMEA, Arquitectura civil española de los siglos I al XVIII, tomo II, Madrid, 1922, Madrid: Giner, 1993, pp. 253-293.

${ }^{6}$ F. MARÍAS FRANCO, El Hospital Tavera de Toledo, Sevilla, 2007, pp. 51-53.

7 F. CHUECA GOITIA, Arquitectura del siglo XVI, Ars Hispaniae, XI, Madrid, 1953, p. 42.

${ }^{8}$ R. DÍEZ DEL CORRAL GARNICA; F. CHECA CREMADES, "Typologie hospitaliere et bienfaisance dans 1'Espagne de la Renaissance"..., p. 121; R. DÍEZ DEL CORRAL GARNICA, "La política hospitalaria en la España del siglo XVI: los hospitales toledanos"..., p. 182; V. NIETO ALCAIDE; A. J. MORALES MARTÍNEZ; F. CHECA CREMADES, Arquitectura del Renacimiento en España, 1488-1599, Madrid, 1989, p. 26.

9 "Aunque la estructura cruciforme pudiera ser tenida como consecuencia lógica de la fusión de cuartos en crujías, procedente de la unión de diferentes organismos organizados 
Es en este contexto en el que tiene lugar un dilatado proceso de experimentación en cuanto a la disposición de las escaleras se refiere, de caja abierta, su trazado vendrá definido espacialmente por su grado de ocultación e integración a los patios en que se inserta. Desde la escalera de ida y vuelta hasta la tipología claustral, se aprecia un lenguaje formal y decorativo tardogótico de influencia mudéjar, presente en los sistemas de cubierta -a base de artesonados de madera y yeserías- junto a la ornamentación de paramentos, balaustradas y pasamanos ${ }^{10}$.

El primer precedente lo encontramos en obras hospitalarias de fundacionales particulares, como la escalera de dos tramos del desaparecido Hospital madrileño de la Concepción de Nuestra Señora "La Latina" (1499-1507). Atribuida al maestro Hazán, bajo el patrocinio de Doña Beatriz Galindo y Don Francisco Ramírez, ubicada originariamente en el vestíbulo principal de entrada del edificio, se encuentra envuelta en una profusa decoración de raigambre tardogótica en pasamanos y antepechos de su doble balaustrada (Fig. 1) ${ }^{11}$.

en torno a un patio, parece más correcto aceptar que los Hospitales de los Reyes Católicos dependen de la tipología hospitalaria italiana medieval, iniciada en Florencia en 1334 por el Ospedale di Santa Maria Nuova y continuada por los edificios de Santa María della Scala de Siena (a. 1440), el Pammatone de Génova (c. 1442), los hospitales de Brescia (1447-52), Pavía, Mantua (1450-72), Milán (1456) y Roma (Santo Spirito in Sassia, 1474-82)". F. MARÍAS FRANCO, "Arquitectura y sistema hospitalario en Toledo en el siglo XVI"..., p. 55.

${ }^{10}$ J. MARTÍNEZ MONTERO, La escalera en la arquitectura civil del siglo XVI en las provincias de Burgos y León, León, 2008, pp. 51-53.

${ }^{11}$ En relación a la escalera del Hospital de la Latina, véase: F. M. TUBINO Y RADA DELGADO, “Puerta y escalera del hospital de la Latina y sepulcros de Francisco Ramírez y Beatriz Galindo en el Monasterio de la Concepción Jerónima de Madrid", Monumentos arquitectónicos de España, Madrid, 1880, pp. 11-12; R. BECERRO DE BENGOA, "Excursión artística por el Madrid Viejo", Boletín de la Sociedad Española de Excursiones, 1894, pp. 2-3; M. AGULLO Y COBO, "El hospital y convento de la Concepción de Nuestra Señora (La Latina)", Villa de Madrid, 48, 1975, pp. 49-58; 50-51, 1976, pp. 26-34; 53,
Tipológicamente eran escaleras claustrales de tres tramos, asimétricas y funcionales, emplazadas en los ángulos de los patios y cubiertas bajo suntuosos artesonados. Como avance decorativo, en los últimos años del gótico las embocaduras se decoraban con molduraciones sinuosas en forma de arcos conopiales, polilobulados o mixtilíneos muy variados.

Continuando con el desarrollo tipológico de la escalera, serán los Hospitales Generales de Santiago de Compostela (15011511) y Granada (1511-1522) donde el maestro Enrique Egas experimente los primeros ejemplos claustrales de tres tramos ${ }^{12}$. De patronato real, destinados a albergar a pobres y enfermos, en el caso concreto de las escaleras del hospital compostelano, por su carácter asimétrico junto al zaguán de entrada y a pesar de que su caja no se encuentra abierta al patio, se conciben como un todo en el interior de un espacio escondido al que se accede, a modo de embocaduras, mediante portadas de arcos mixtilíneos (Fig. 2).

Sin embargo, tal y como veremos, el ejemplo que mejor define la experimentación espacial en la arquitectura asistencial española del siglo XVI, es sin duda la escalera del Hospital de Santa Cruz en Toledo, obra fundacional testamentaria del “Gran Cardenal” Don Pedro González de

1976, pp. 19-26; J. M. TOMÉ BONA, “El hospital de la Concepción Francisca, vulgo de la Latina", Anales del Instituto de Estudios Madrileños, XXVII, 1989, pp. 307-316.

\footnotetext{
${ }^{12}$ Un pormenorizado estudio de ambos hospitales, con especial atención a las escaleras emplazadas en los ángulos de los patios de cada uno de ellos, puede verse en las obras: M. LUCAS ÁLVAREZ, El Hospital Real de Santiago (1499-1531), Santiago de Compostela, 1964; J. M. AZCÁRATE RISTORI, “El Hospital Real de Santiago: la obra y los artistas", Compostellanum, X, 4, 1965, pp. 507-522; C. FÉLEZ LUBELZA, El Hospital Real de Granada, Granada, 1979, pp. 109-110; D. GARCIA GUERRA, El Hospital Real de Santiago (1499-1804), La Coruña, 1983; A. A. ROSENDE VALDÉS, El Grande y Real Hospital de Santiago de Compostela, Santiago de Compostela, 1999, pp. 85-91; M. E. CAMBIL HERNANDEZ, Los hospitales de Granada (siglos XVI-XXI): tipologías, catálogo e historia, Granada, 2011.
} 
Mendoza. Punto de partida para la proyección del propio Covarrubias de la tipología de escalera doble claustral y caja abierta en el Hospital del Cardenal Juan Pardo Tavera, denominado de Afuera o de San Juan Bautista de Toledo (1541-1542), ubicada en el eje central del edificio, obra que tomaría como referente a la recién concluida escalera del Alcázar de Madrid (1536-1547). Este tipo de escalera biclaustral constituiría un auténtico referente en la concepción articuladora de los espacios, como vínculo de comunicación entre sendos patios ${ }^{13}$.

Entre las numerosas muestras de las tipologías de escaleras en edificios asistenciales en las que todavía perdura el modelo claustral, destacamos la escalera de dos tramos y caja abierta bajo bóveda esquifada del Hospital de Santiago de Úbeda (1560-1575), obra del arquitecto Andrés de Vandelvira y fundación del Secretario de Estado de Felipe II Don Diego de los Cobos y Molina (Fig. 3) ${ }^{14}$.

Otras escaleras de tres tramos, caja abierta y corte clasicista encontramos en el Hospital del cambista Simón Ruiz Embito en Medina del Campo (1593-1598), trazada por el maestro de cantería Juan de Tolosa y modificada por Juan de Nates; y en el Hospital burgalés de Nuestra Señora del Rosario

\footnotetext{
13 Sobre la escalera del Hospital Tavera, véase: C. WILKINSON ZERNER, "Style and spatial organization. The Lineage of the Spanish Imperial Staircase", The Hospital of Cardinal Tavera in Toledo. A documentary and stylistic study of spanish architecture in the mid-sixteenth century, Tesis Doctoral, Universidad de Yale, 1968, Nueva YorkLondres, 1977, pp. 151-188; F. MARÍAS FRANCO, El Hospital Tavera de Toledo..., p. 62.

${ }^{14}$ A. MORENO MENDOZA, El arquitecto Andrés de Vandelvira en Úbeda: una aproximación a la arquitectura del Renacimiento en la Alta Andalucía, Sevilla, 1979; AA.VV., La arquitectura del Renacimiento en Andalucía. Andrés de Vandelvira y su época, Sevilla, 1992; A. MORENO MENDOZA, Úbeda renacentista, Madrid, 1993; P. A. GALERA ANDREU, Andrés de Vandelvira, Madrid, 2000; A. MORENO MENDOZA, La Úbeda de Vandelvira, Sevilla, 2005; A. UREÑA UCEDA, La escalera imperial como elemento de poder: Sus orígenes y desarrollo en los territorios españoles en Italia durante los siglos XVI y XVII, Madrid, 2007, pp. 68-72.
}

en Briviesca, obra proyectada por Rodrigo de Rasines en 1584 y materializada por Diego de Sisniega durante los años 1604 y 1606 (Fig. 4$)^{15}$.

\section{LA ESCALERA DEL HOSPITAL DE SANTA CRUZ EN TOLEDO: NUEVAS HIPÓTESIS SOBRE SU AUTORÍA Y PROCESO CONS- TRUCTIVO}

Realizado bajo el patrocinio del cardenal de España y arzobispo de Toledo Don Pedro González de Mendoza (1428-1495), el Hospital de Santa Cruz se edificó acorde a una estructura cruciforme, tal y como venía siendo habitual en las obras hospitalarias de impulso regio o privado en la España del siglo XVI. Dedicado al cuidado de niños abandonados, según se desprende de las mandas testamentarias del Gran Cardenal, "lo distribuya a los pobres enfermos e niños expósitos e personas menesterosas", compartía protagonismo junto a otros hospitales especializados en la ciudad, como el de San Antón, el del Rey, el del Nuncio y el de Santiago de los Caballeros $^{16}$.

La historiografía tradicional atribuye su traza inicial al maestro Enrique Egas y una posterior intervención de Alonso de Covarrubias, todo ello entre los años 1504 y $1524^{17}$. En cuanto a su escalera principal,

\footnotetext{
$\overline{15}$ I. CADIÑANOS BARDECI, “El hospital de Nuestra Señora del Rosario de Briviesca", Boletín de la Institución Fernán González, 214, 1997, pp. 11-24; L. NAVARRO GARCÍA, El hospital general de Simón Ruiz en Medina del Campo. Fábrica e idea, Valladolid, 1998; B. ALONSO RUIZ, "El monasterio de Santa Clara y el hospital de Nuestra Señora del Rosario en Briviesca (Burgos)", Archivo Ibero-Americano, 64, 247-248, 2004, pp. 421-446.

${ }^{16}$ A. ÁLVAREZ ANCIL, Copia fiel y exacta del Testamento del Cardenal Arzobispo que fué de Toledo Don Pedro González de Mendoza, que original y auténtico existe en el Archivo de la Excma. Diputación provincial de Toledo, Toledo, 1915, p. 20.

${ }^{17}$ Numerosos historiadores han analizado el proceso constructivo del hospital, sin centrarse exhaustivamente en el papel de la escalera: J. M. AZCÁRATE RISTORI, "Alonso de Covarrubias en el Hospital de
} 
objeto de análisis del presente trabajo, ubicada en el patio meridional (orientación sureste) junto al zaguán de entrada, cuenta con una superficie de $57,35 \mathrm{~m}^{2}$ de caja, una altura de $12,85 \mathrm{~m}$ y una anchura media de cada uno de los peldaños por tramo de 2,40 m; fue proyectada por Egas hacia 1504-1505 y materializada, como veremos, por Alonso de Covarrubias junto a alguno de sus colaboradores entre los años 1530 y 1540 (Fig. 5) ${ }^{18}$.

En opinión de Marías Franco, siguiendo al especialista Harold Edwin Wethey, "este tipo de escalera, tan español, de tres tramos en caja cuadrada, parece ser creación de Egas a partir de modelos tardogóticos como el del colegio de San Gregorio de Valladolid... Los arcos rebajados de la escalera del hospital llevan la impronta de Egas; la decoración, superpuesta, debe ser obra de Covarrubias, hacia 1530"19. En nuestra opinión, la tipología de escalera claustral de tres tramos y caja abierta, de la que el Hospital de Santa Cruz es su mejor exponente, cuenta con modelos más cercanos en el tiempo en los focos artísticos de Burgos y Valladolid, a partir de los cuales podría haber ido evolucionando progresivamente de la mano de maestros de obras como Felipe Bigarny o Luis de Vega, viéndose eclipsados por el papel protagonista del foco toledano y su irradiación a través de la obra de Alonso de Covarrubias hacia Guadalajara, Madrid, Alcalá de Henares y Valencia.

Como único vestigio de la construcción emprendida por Egas en los primeros momentos de la fábrica, entre 1504 y 1514,

Santa Cruz de Toledo", Archivo Español de Arte, XXIII, 89, 1950, pp. 79-80; F. MARÍAS FRANCO, "Del gótico al manierismo: el hospital de Santa Cruz", $V$ Simposio Toledo Renacentista, tomo III, Toledo, 1975, Madrid, 1980, pp. 125-159; R. DÍEZ DEL CORRAL GARNICA, “La introducción del Renacimiento en Toledo: el Hospital de Santa Cruz", Academia, 62, 1986, pp. 161-181.

18 Agradecemos a Don Felipe Delgado Laguna, arquitecto responsable del levantamiento planimétrico del Museo de Santa Cruz en el año 2009, los datos facilitados sobre mediciones de la escalera.

${ }^{19}$ F. MARÍAS FRANCO, "Del gótico al manierismo: el hospital de Santa Cruz"..., pp. 139-140. se ha de señalar la presencia no solo de uno, sino de dos arcos rebajados y moldurados en el interior de la triple arcada de ascenso y descenso de la escalera, hecho que demuestra la existencia de una escalera previa de un solo vano de acceso y realizada en un lenguaje tardogótico, de la que partiría Covarrubias para intervenir en un espacio trazado previamente ${ }^{20}$.

Si el arco inferior queda visible bajo la triple arcada de arcos carpaneles y de medio punto de la embocadura (a modo de arco del triunfo), el arco superior persiste aún hoy oculto debajo de la ornamentación de yesería que se colocó durante un segundo momento constructivo de la fábrica, para evitar ser visto en su ascenso por la escalera (Fig. 6).

Este tipo de disposición de caja abierta, en la que un gran arco escarzano preside la embocadura de la escalera, tiene como precedentes en el foco castellano a las escaleras del Palacio de los Condes de Miranda en Peñaranda de Duero (1520-1535) y de los Dueñas en la localidad vallisoletana Medina del Campo (1528-1530) ${ }^{21}$. En cuanto

\footnotetext{
${ }^{20}$ Opinión vertida por: F. MARÍAS FRANCO, "Del gótico al manierismo: el hospital de Santa Cruz"..., p. 136. "Debía existir ya la caja de la escalera, pues el gran arco rebajado del primer piso presenta una molduración y decoración vegetal, góticas, que pertenecen al estilo de Egas". Y refrendada por: R. DÍEZ DEL CORRAL GARNICA, "La introducción del Renacimiento en Toledo: el Hospital de Santa Cruz"..., p. 173. "El patio principal del hospital, junto con la escalera, han llamado poderosamene la atención de todos los historiadores. Ha sido considerado como una de las composiciones más bellas de todo nuestro renacimiento, a pesar de observarse que la unión entre patio y escalera se hacía de una manera bastante torpe, por medio de un gran arco rebajado con formas góticas".

Ambos especialistas tan solo hablan del arco de la embocadura de la escalera para justificar la intervención previa de Egas y no del que queda oculto en la desembocadura de la misma, que como veremos será fundamental para determinar el proceso constructivo de la escalera.

21 La embocadura del palacio burgalés está presidida por un arco carpanel o apainelado, geminado y moldurado, mientras que la del palacio medinense es de tipo escarzano como en el caso del propio hospital
} 
a la apertura de la tribuna en el piso superior, la disposición de una ventana geminada bajo arco carpanel en el palacio burgalés, deja paso, en el caso de su homóloga vallisoletana, a una triple arcada apainelada (Fig. 7$)^{22}$.

Documentalmente, el periodo de realización de la escalera ha sido analizado por Marías Franco y posteriormente por Díez del Corral, quienes recogen, como testimonio fechado el 2 de mayo de 1535, las condiciones de las tareas a realizar en el hospital por el cantero Juan de Plasencia, por las que se contratan sus servicios para reparar el patio, mencionándose a Alonso de Covarrubias como fiador de la obra ${ }^{23}$. Una nueva lectura

toledano. J. MARTÍNEZ MONTERO, “La escalera del palacio de los condes de Miranda de Peñaranda de Duero, Burgos", De Arte, 4, 2005, pp. 75-87; J. MARTÍNEZ MONTERO, Arquitectura nobiliaria del Renacimiento en Burgos y provincia, Sarrebruck, 2013, pp. 99-114.

22 Sobre la escalera de la casa del doctor Diego Beltrán, más conocida como Palacio de los Dueñas, proyectada y realizada entre los años 1528 y 1530 por el arquitecto Luis de Vega, junto a los maestros Pedro de la Piedra y Diego de Soba, véase: E. GARCÍA CHICO, “El Palacio de los Dueñas de Medina del Campo", B.S.A.A., XVI, 1950, pp. 87-110; J. URREA FERNÁNDEZ, "El arquitecto Luis de Vega (h. 1495-1562)", A introduçao da arte da Renascença na Península Ibérica, Coimbra, 1981, pp. 162-164.

${ }^{23}$ Archivo Histórico Provincial de Toledo (AHPT.). PN. Leg. 1390, fol. 385. 2 de mayo de 1535. "Yten se an de retundir todos los arcos altos con sus envecaduras de dentro e de fuera descostrando muy bien las juntas y tornandolas a henchir de yeso de çedaço y endereçar y linpiar las moladaduras con sus formones dentados de manera que los dichos arcos queden linpios syn lechada de cal ni yeso conforme a los tres arcos baxos de la entrada del escalera".

Documento citado por: V. GARCÍA REY, "El famoso arquitecto Alonso de Covarrubias (datos inéditos de su vida y obras): I Datos biográficos", Arquitectura, 97, 1927, p. 172. Reproducido por: F. MARÍAS FRANCO, "Del gótico al manierismo: el hospital de Santa Cruz"..., pp. 147-148.

Opinión recogida por: R. DÍEZ DEL CORRAL GARNICA, "La introducción del Renacimiento en Toledo: el Hospital de Santa Cruz" ..., pp. 173-174; R. DÍEZ DEL CORRAL GARNICA, Arquitectura y mecenazgo. La imagen de Toledo en el Renacimiento..., p. 258; Y. FUERTES GARCÍA, “Infancia y marginación en la época de los Reyes Católicos. El hospital de Santa Cruz de Toledo: un nuevo lenguaje artístico y social", La arquitectura del documento e interpretación del mismo retrasaría la fecha de realización de la escalera y la alejaría de la tradicional atribución a Covarrubias.

El hecho de que se pusiera como modelo testimonial de las intervenciones a "los tres arcos baxos de la entrada del escalera", no implicaría que el conjunto estuviera completamente acabado, ni siquiera que el propio Covarrubias hubiera construido la totalidad de la misma, puesto que la permanencia de ambos arcos escarzanos en el interior de la caja evidenciaban la existencia previa de una escalera. Es por ello que, paradójicamente ante este hecho, el inicio de la remodelación diera comienzo hacia 1534 por la propia embocadura, con el fin de dejar semioculta la disposición de Egas.

En el caso de que Covarrubias hubiera proyectado y materializado de nueva planta el total de la escalera, no hubiera dejado visibles ambas arcuaciones, ni siquiera hubiera cometido errores estructurales tan evidentes en su conjunto como las desafortunadas uniones de los tramos, la asimetría de los sillares del paramento o el ensamblado de los paneles decorativos.

Otro de los aspectos que más nos llama la atención es el hecho de que las arcuaciones, su molduración y ornamentación, se adapten torpemente al trazado de los arcos escarzanos, así como que el primer tramo de la escalera arranque al mismo nivel que el paramento del tercer tramo, para cuya unión con la desembocadura se emplee como recurso arquitectónico de mayor profundidad y sensación de espacialidad, una bovedilla con motivos florales acasetonados, similar a la utilizada en la escalera de la Casa de Juan de Arenillas, sede del convento de Carmelitas Descalzas de la Purísima Concepción o de la Imagen, en Alcalá de Henares (1530-1535).

La decoración de frisos, molduras y pilastras, junto a la balaustrada y los cuatro

tardogótica castellana entre Europa y América, Madrid, 2011, pp. 358-360. 
montantes que rematan el comienzo y fin de cada tramo, presentan una labor escultórica mucho más refinada que el conjunto de la escalera, en cuya desembocadura se aprecian diferencias notables con respecto a la triple arcada de la embocadura, cuyos capiteles, mucho más toscos que los del nivel inferior, se disponen en consonancia a los existentes en el piso superior del patio.

En nuestra opinión, debido a los problemas de replanteo con que contó la obra, la intervención de Covarrubias, se centró en un primer momento en la triple arcada del nivel inferior, no así en la desembocadura, en cuyo intradós de los arcos se mantienen los mismos motivos decorativos que en el resto de las arcuaciones del piso superior, por lo que consideramos que este otro nivel de la escalera pertenece a una labor de fábrica coetánea a la reforma del patio meridional y por tanto, posterior en el tiempo.

En cuanto a la decoración de los motivos heráldicos, entre los que se incluyen la cruz potenzada de Jerusalén y el escudo cardenalicio, ubicados en las enjutas interiores de los arcos y en dos puertas abiertas en el paramento inferior de la escalera, así como en el remate del montante del primer tramo de la misma, creemos son motivo de una intervención más tardía, si bien las restauraciones posteriores han tratado de recuperar estos emblemas, con el fin de ensalzar la labor de patrocinio del cardenal en uno de los sitios más representativos del edificio: la propia escalera monumental.

Ambas puertas es muy probable que se abrieran con posterioridad a la construcción de la propia escalera, ya que se aprecia una diferencia notable en el acabado decorativo de las jambas y rosca del arco con respecto al resto de relieves de la escalera, así como una ruptura en la disposición a tresbolillo de los casetones almohadillados del paramento en el que se encuadran (Fig. 8) ${ }^{24}$.

\footnotetext{
${ }^{24}$ En la actualidad, la puerta izquierda permite el descenso mediante una escalera de ida y vuelta a la sala y almacenes de la sección de arqueología, con una cota de -5,08 m.
}

Muchos de estos casetones fueron sustituidos, tal y como veremos más adelante, en restauraciones más tardías.

La ornamentación de la que es objeto la escalera se centra fundamentalmente en los paneles decorativos de la embocadura, que presentan dos parejas de querubines a cada lado, flanqueando el escudo del cardenal y dispuestos sobre cuernos de la abundancia ornados con decoración vegetal a candelieri; mientras que los bajorrelieves de la desembocadura enfatizan nuevamente la cruz cardenalicia entre cornucopias y motivos vegetales a modo de aureolas conmemorativas.

En cuanto al barandal y los montantes de la escalera, presentan ciertas semejanzas con los que aparecen en su coetánea, la escalera del Palacio Arzobispal de Alcalá de Henares; si bien los balaustres de ambas escaleras pudieron ser renovados a inspiración de los originales, en el caso de la escalera toledana nos encontramos nuevamente con cuatro montantes muy similares a la decoración de las ménsulas exteriores existentes en las lumbreras o ventanas del Castillo de Chambord $^{25}$. Este tipo de motivo ornamental es utilizado nuevamente en la escalera del Convento alcalaíno de Carmelitas Descalzas (Fig. 9) ${ }^{26}$.

Tales influencias francesas en la obra de Covarrubias, tienen justificación documental por la presencia, en la obra del

\footnotetext{
${ }^{25}$ Se ha de dejar constancia de que prácticamente la totalidad de los montantes de la escalera, incluyendo los remates florales a base de búcaros y rosetas, han sido repuestos, reconstruidos y reinterpretados en las restauraciones historicistas del pasado siglo XX.

${ }^{26}$ Este tipo de montantes fueron utilizados por el propio Covarrubias junto a Juan de Álava en 1532, en las trazas dadas para las escaleras del Colegio Mayor del arzobispo Fonseca en Salamanca. Acerca de las escaleras del Colegio Fonseca, consúltese: M. SENDÍN CALABUIG, El Colegio Mayor del arzobispo Fonseca en Salamanca, Salamanca, 1977, pp. 122-123; A. CASTRO SANTAMARÍA, Juan de Álava, arquitecto del Renacimiento, Salamanca, 2002, pp. 450-451; A. CASTRO SANTAMARÍA, El Colegio Mayor del arzobispo Fonseca o de los Irlandeses, Salamanca, 2003, pp. 53-55.
} 
hospital, de entalladores franceses como Guillén Colís y Martín de Blas, que ya habían trabajado en la fachada del Hospital de Santiago de Compostela, obra de Egas hacia 1520 y donde se aprecian similitudes en los candeleros que aparecen como remates de la portada principal, con respecto a los montantes de las escaleras ${ }^{27}$.

En cuanto a la decoración del paramento inferior de la escalera, similar en su disposición a la de la escalera alcalaína, su iconografía se ve reducida a la mínima expresión a través de la repetición de casetones almohadillados en los que se disponen arcos ciegos junto a la cruz potenzada del promotor. Ambos motivos, tal y como hemos apuntado, se emplean reiterativamente en la caja de la escalera, tanto en las molduras como en las enjutas de las arcuaciones ${ }^{28}$.

Llegado a este punto y atendiendo a determinados aspectos expuestos prevamente, nos planteamos las siguientes cuestiones: ¿hasta qué punto Covarrubias intervino en la escalera trazada por Egas?, ¿su materialización es anterior, contemporánea o posterior incluso a la del Palacio Arzobispal de Alcalá de Henares?, ¿puede la escalera haber sido realizada por otros maestros cercanos al círculo de Covarrubias y no de manera directa por el maestro toledano? (Fig. 10).

Para dar respuesta a estas y otras preguntas, establecemos tres periodos en la labor de fábrica de la escalera: un primer momento acontecido tras la construcción del hospital (1504-1514) por Enrique y Antón Egas, en el que el propio Covarrubias colaboraría formándose como escultor en la obra durante los años 1517-1524 y en el que se proyectaría una primera escalera claustral

\footnotetext{
${ }^{27}$ B. BEVAN, Historia de la arquitectura española, Barcelona, 1950, p. 215.

28 Puesto que el propio Covarrubias evoluciona constructiva y ornamentalmente en su trayectoria como arquitecto, en el trazado de las escaleras no va a ser menos, en las que imprimirá un clasicismo estructural y decorativo.
}

de tres tramos, de la que conservamos los dos arcos escarzanos en que se encuadra la escalera actual.

Un segundo momento, comprendido entre los años 1525 y 1535, en el que daría comienzo la decoración de la fachada y el zaguán principal del hospital, junto a la remodelación de la embocadura de la escalera. Finalmente, entre 1536 y 1540, tendría lugar la reforma integral de los tramos, paramento y desembocadura de la nueva escalera, contemporánea a la obra de reparación del patio y en la que artistas contratados por el propio Covarrubias desarrollarían un nuevo lenguaje decorativo, mucho más sobrio en el caso del paramento toledano que el desarrollado en la escalera alcalaína, previsiblemente motivado por la ausencia del maestro en la toma de decisiones de una obra cuyo programa iconográfico se centra de manera evidente en perpetuar la labor de promoción de su comitente, a través de la reiteración de los emblemas cardenalicios a lo largo de toda la escalera ${ }^{29}$.

A la espera de nuevos datos documentales que corroboren su participación directa y constante en la obra, en nuestra opinión, su intervención se centraría no tanto en la traza, ya proyectada por Egas, sino en la labor ornamental del paramento, pilastras y capiteles del piso inferior, junto a balaustradas, pasamanos y montantes del conjunto de la escalera. Por tanto, su ejecución se dilataría en el tiempo abarcando cronológicamente los años 1525/1530 hasta 1540, momento en que la escalera del Palacio Arzobispal se encontraba en plena construcción, es por ello que aunque la toledana se comenzara a levantar casi un década antes que la alcalaína, motivada por los problemas de replanteo iniciales, su materialización no se culminaría hasta finales de la década de los treinta, por lo que consideramos que la

\footnotetext{
${ }^{29}$ Este hecho viene avalado por la vinculación de Covarrubias, a través de canteros y albañiles, con la fábrica del hospital hasta pasada la segunda mitad del siglo XVI, simultaneándolo con numerosos encargos para otras obras.
} 
dirección de Covarrubias se produjo de forma paralela en ambos ejemplos.

Otro de los aspectos más notables en el proceso de su fábrica, reside en la hipótesis de dotar a la escalera claustral de tres tramos de una fuerte axialidad y simetría, propia del avance en la experimentación tipológica hispana en estas primeras décadas, completándose, según señala Sánchez-Robles Beltrán, mediante la proyección de otra escalera claustral al otro lado del zaguán de entrada, quedando ambas adosadas a los muros laterales de éste, formando parte de un programa especular propio de la tipología hospitalaria del quinientos ${ }^{30}$.

\section{RESTAURACIÓN Y MUSEALIZACIÓN DE LA ESCALERA}

En cuanto a las intervenciones restauradoras en las que se vio inmersa la escalera, fundamentales a la hora de analizarla en todo su conjunto, se ha de destacar que tuvieron lugar de manera progresiva en diferentes fases, motivadas inicialmente por el estado de abandono en que se encontraba el hospital desde finales del siglo XIX. Síntomas evidentes se observaban en el cimentado de los casetones del paramento, la inexistencia de balaustres casi en la totalidad de los tramos, junto a la delimitación funcional de espacios en el edificio a través de elementos tan significativos como el hecho de que la puerta interior aparezca cegada o que se observe la presencia de una reja con una puerta de acceso en la desembocadura (Fig. 11).

Hacia 1920, según podemos constatar en testimonios gráficos de estas fechas, tienen lugar las primeras reposiciones y sustituciones de aquellos elementos que

${ }^{30}$ Formulación hipotética realizada por: C. SÁNCHEZ-ROBLES BELTRÁN, "Las escaleras post-medievales: Alonso de Covarrubias y la escalera imperial", Jornadas Nacionales sobre el Renacimiento Español, Pamplona-Estella, 1990, Príncipe de Viana, Pamplona, Anejo 10, 1991, p. 287. se habían visto resentidos con el paso del tiempo (escudo del promotor, montantes y balaustres), llegando incluso a apuntalarse la caja de la escalera, cubierta bajo un maltrecho artesonado acasetonado de madera ${ }^{31}$.

El arquitecto José Manuel González Varcárcel, entre los años 1955 y 1962, llevó a cabo importantes obras de conservación en el hospital, centradas en la sustitución de numerosos balaustres de la escalera, muchos de ellos desaparecidos y otros tapados con un recrecido de cemento. También intervino en la recreación de parte del pasamanos y en la disposición de enfoscados y revocos en las paredes interiores de su caja (Fig. 12).

Finalmente, durante los años 1979 y 1983, bajo la dirección del arquitecto Antonio García Vereda, se realizaron obras de restauración y acondicionamiento de espacios para su adaptación como sede del Museo de Santa Cruz. Mientras que entre los años 1994 y 1995, el servicio de Monumentos del Instituto del Patrimonio Histórico Español dirigido por el arquitecto Ángel Luís Sousa, el aparejador Marcos Toribio y la restauradora Concha Cirujano, desempeñó un trabajo de consolidación en el conjunto de la escalera. Dicha intervención se completó con la acometida en el año 2006 por la empresa CPA Conservación del Patrimonio Artístico (Fig. 13) ${ }^{32}$.

En la actualidad, la escalera ha perdido toda función propagandística y de exaltación del poder del promotor para la que

\footnotetext{
${ }^{31}$ Numerosos testimonios documentales y visuales han dejado constancia del estado en que se encontraba la balaustrada, el pasamanos y algunos motivos decorativos de la escalera. J. PASTOR GÓMEZ, "Por la urgente restauración del Hospital de Santa Cruz", Arte Español, XIX, 1952, pp. 37-68.

${ }^{32}$ M. C. OLALLA SÁNCHEZ, Notas histórico artísticas en torno a la escalera de Covarrubias del Hospital de Santa Cruz de Toledo, trabajo de investigación inédito, Instituto del Patrimonio Histórico Español, Madrid, 26 de octubre de 1994; CPA CONSERVACIÓN DEL PATRIMONIO ARTÍSTICO, Servicio de Restauración de la Escalera de Covarrubias del Museo de Santa Cruz de Toledo, tomo II, Toledo, 2006, pp. 51-55.
} 
fue concebida, pasando de ser una pieza clave, dentro de un edificio asistencial que proporcionaba curación a los enfermos y ayuda

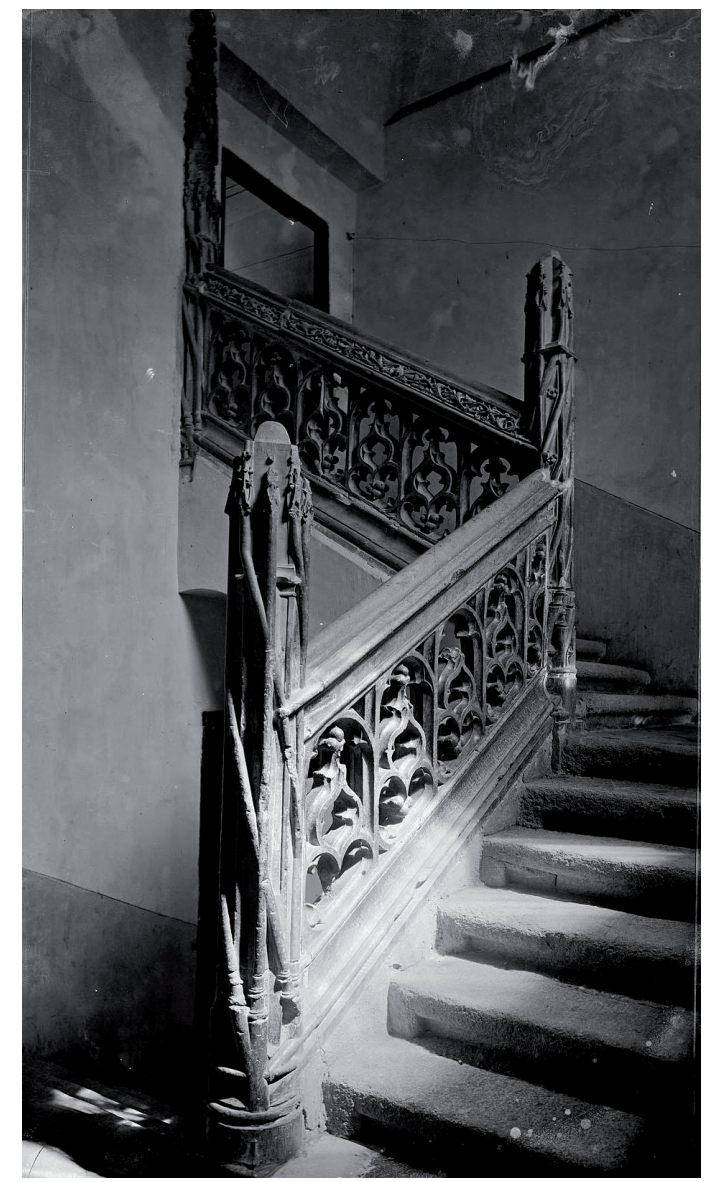

- Fig.1. Vista de la escalera del Hospital de la Latina en su ubicación original. J. A. GAYA NUÑO, La arquitectura española en sus monumentos desaparecidos, Madrid, 1961, p. 241. a los más necesitados, a verse inmersa en un recorrido museográfico dentro del itinerario del Museo de Santa Cruz ${ }^{33}$.

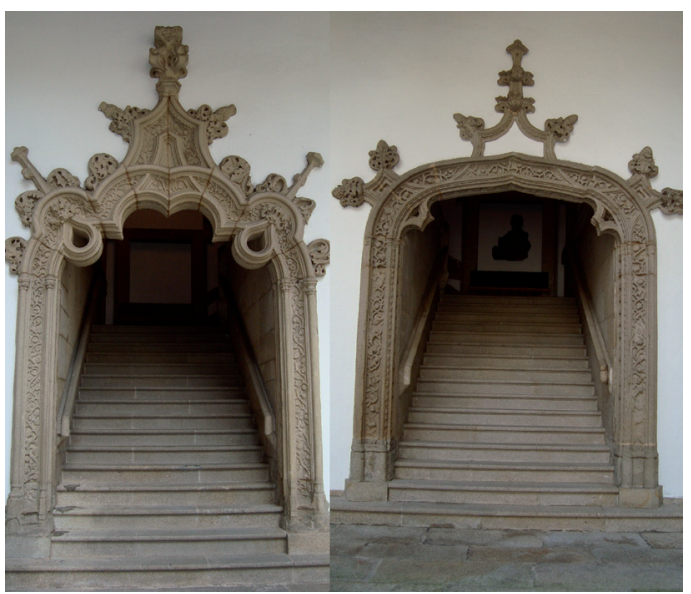

- Fig.2. Embocaduras de las escalera abiertas a los patios anteriores del Real Hospital de Santiago de Compostela, La Coruña. Fotografías del autor.

${ }^{33}$ En 1846, bajo propiedad del Ministerio del Ejército, el hospital se convierte en sede del Colegio General Militar, siendo declarado Monumento Nacional en 1902 al amparo del Ministerio de Instrucción Pública, constituyéndose, por decreto 997/1961 de 25 de mayo, bajo la denominación de Museo de Santa Cruz y albergando desde entonces la sede definitiva del primitivo Museo Arqueológico y de Bellas Artes de Toledo. M. REVUELTA TUBINO, "El Museo de Santa Cruz y sus filiales", Toletum, Toledo, 6, 1973, pp. 61-145.

De titularidad estatal, desde el año 1984 está gestionado por la Junta de Comunidades de Castilla-La Mancha y alberga las secciones de Arqueología, Bellas Artes y Artes Industriales. 


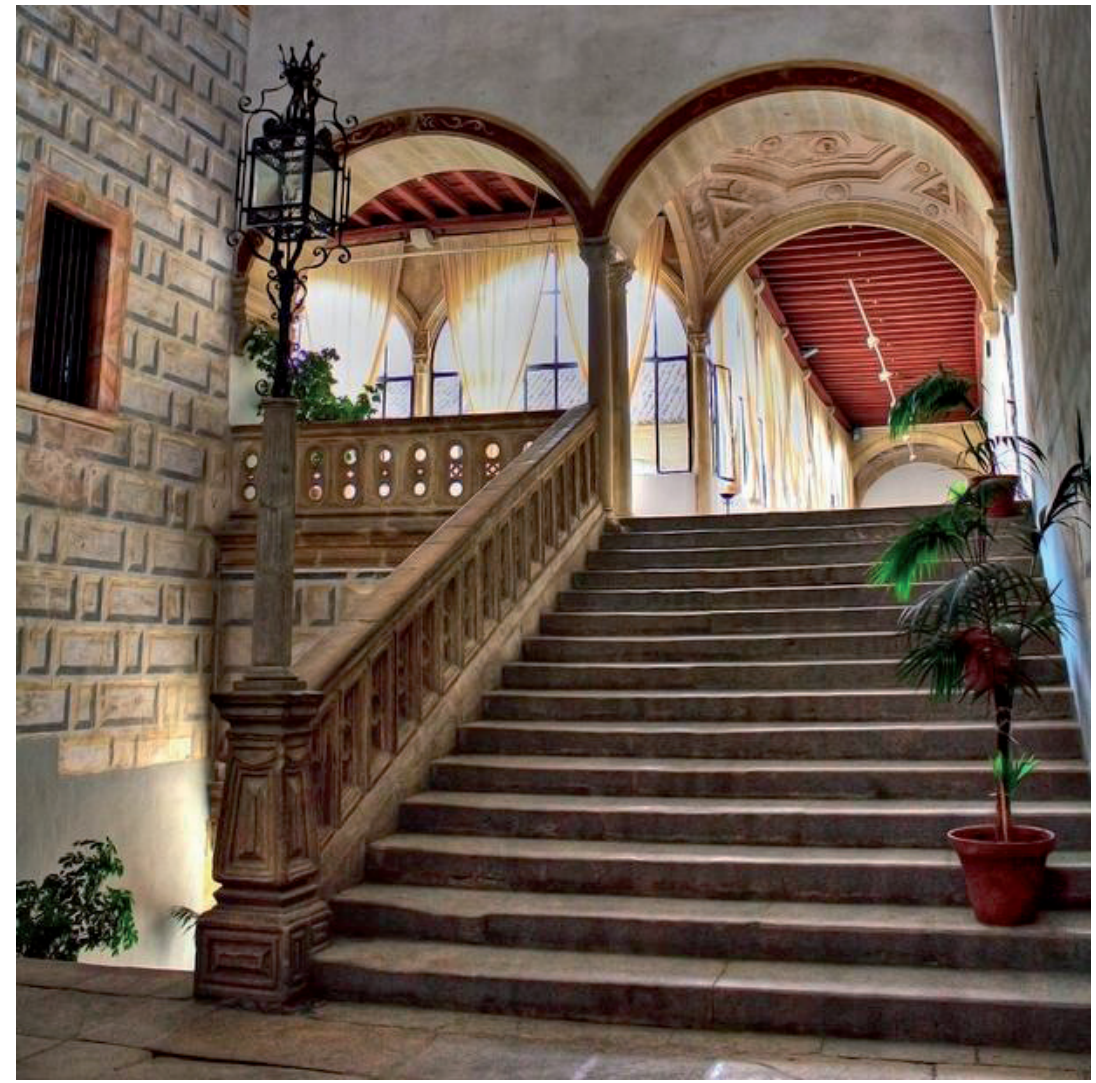

- Fig.3. Vista interior de la escalera del Hospital de Santiago en Úbeda, Jaén. Fotografía del autor.

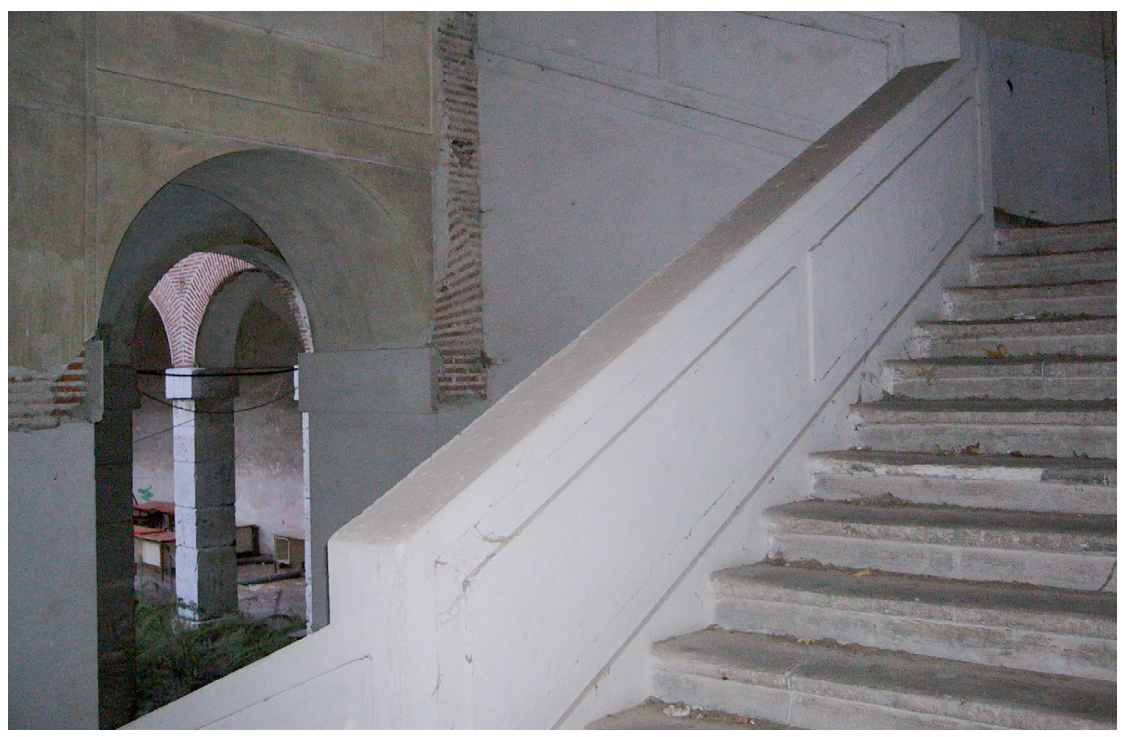

- Fig.4. Escalera del Hospital de Simón Ruiz Embito en Medina del Campo, Valladolid. Fotografía del autor. 


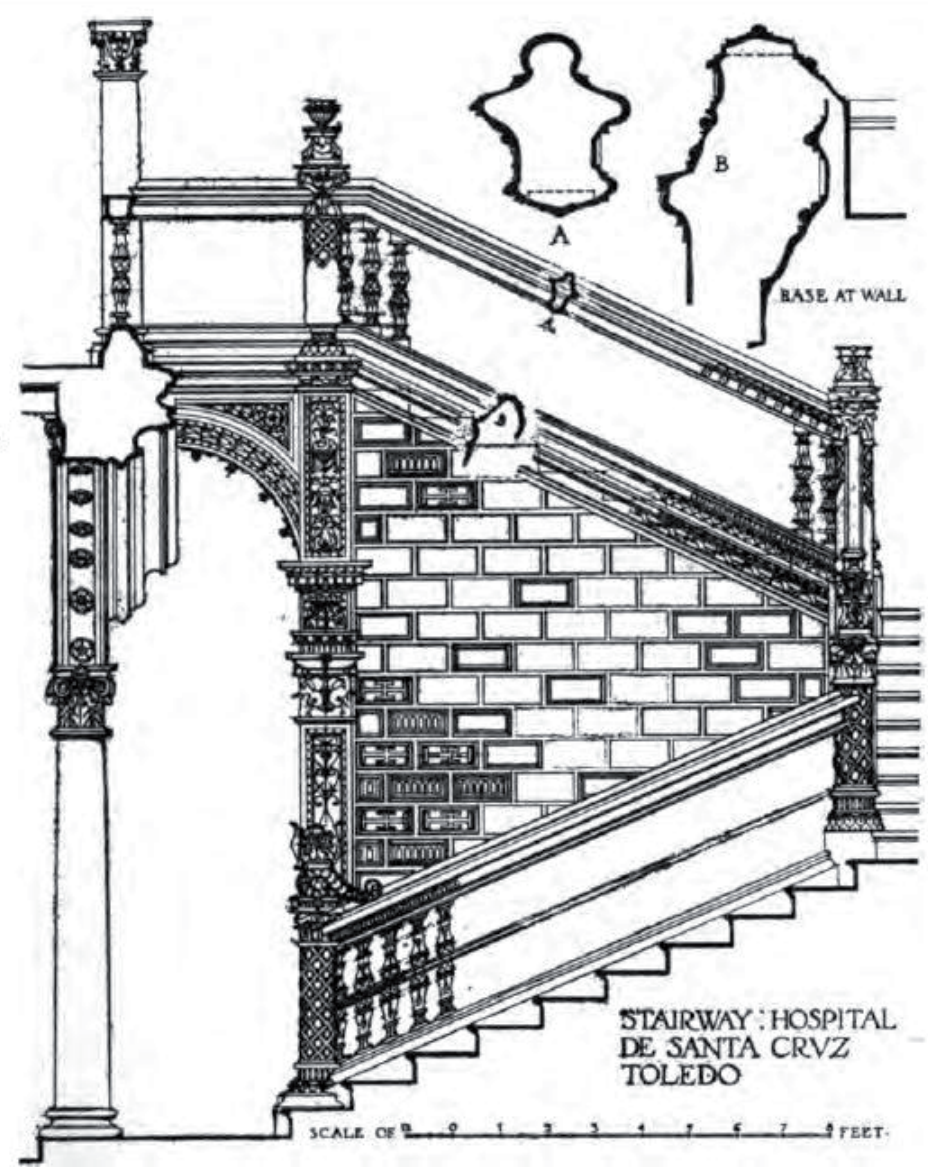

- Fig.5. A. BYNE; M. STAPLEY, Spanish architecture of the sixteenth century, Nueva York, Londres, 1917, Plate III, p. 19.
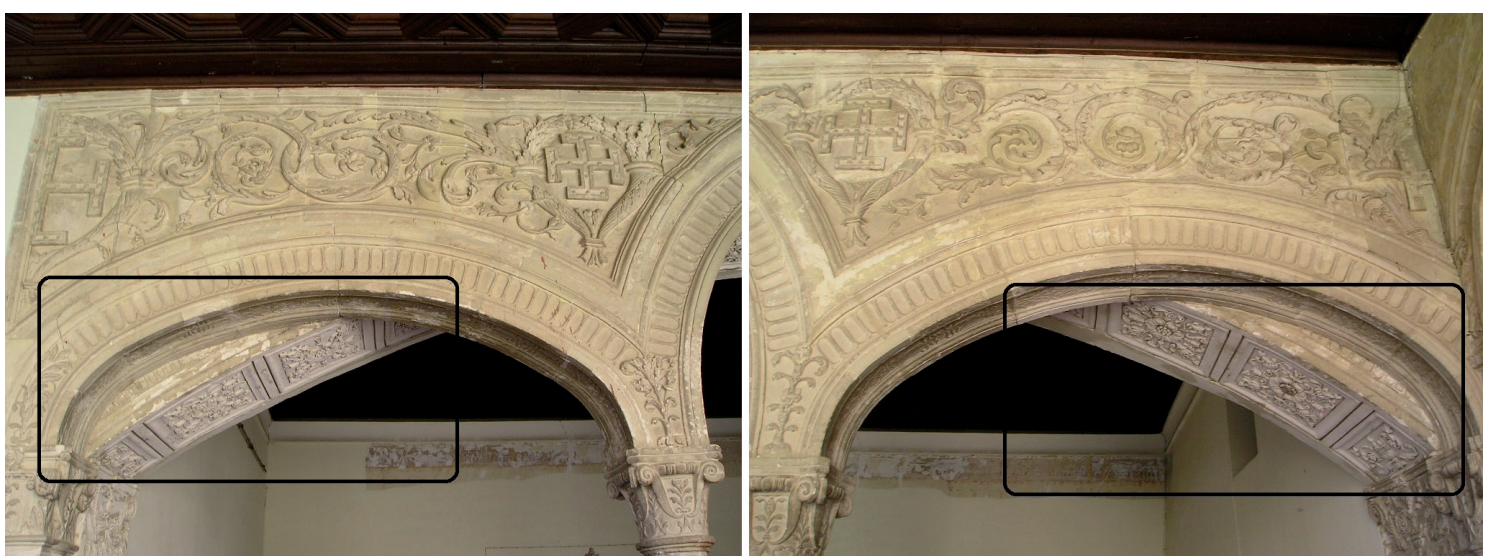

- Fig.6. Vistas del arco superior donde se aprecia la moldura del mismo bajo la decoración de yesería en la escalera del Hospital de Santa Cruz, Toledo. Fotografías del autor. 


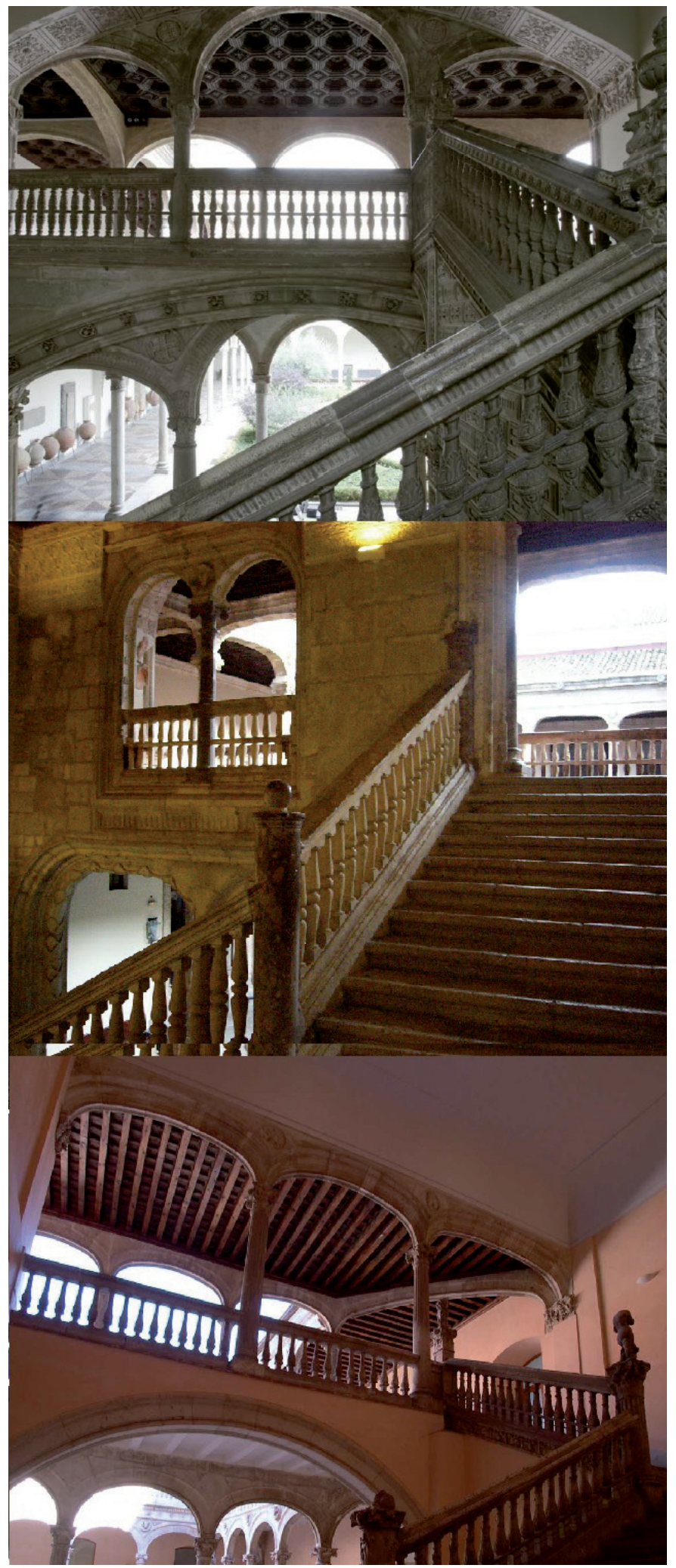

- Fig.7. Vistas de las embocaduras y tribunas de las escaleras del Hospital de Santa Cruz en Toledo, el Palacio de los Condes de Miranda en Peñaranda de Duero, Burgos y del Palacio de los Dueñas en Medina del Campo, Valladolid. Fotografías del autor. 

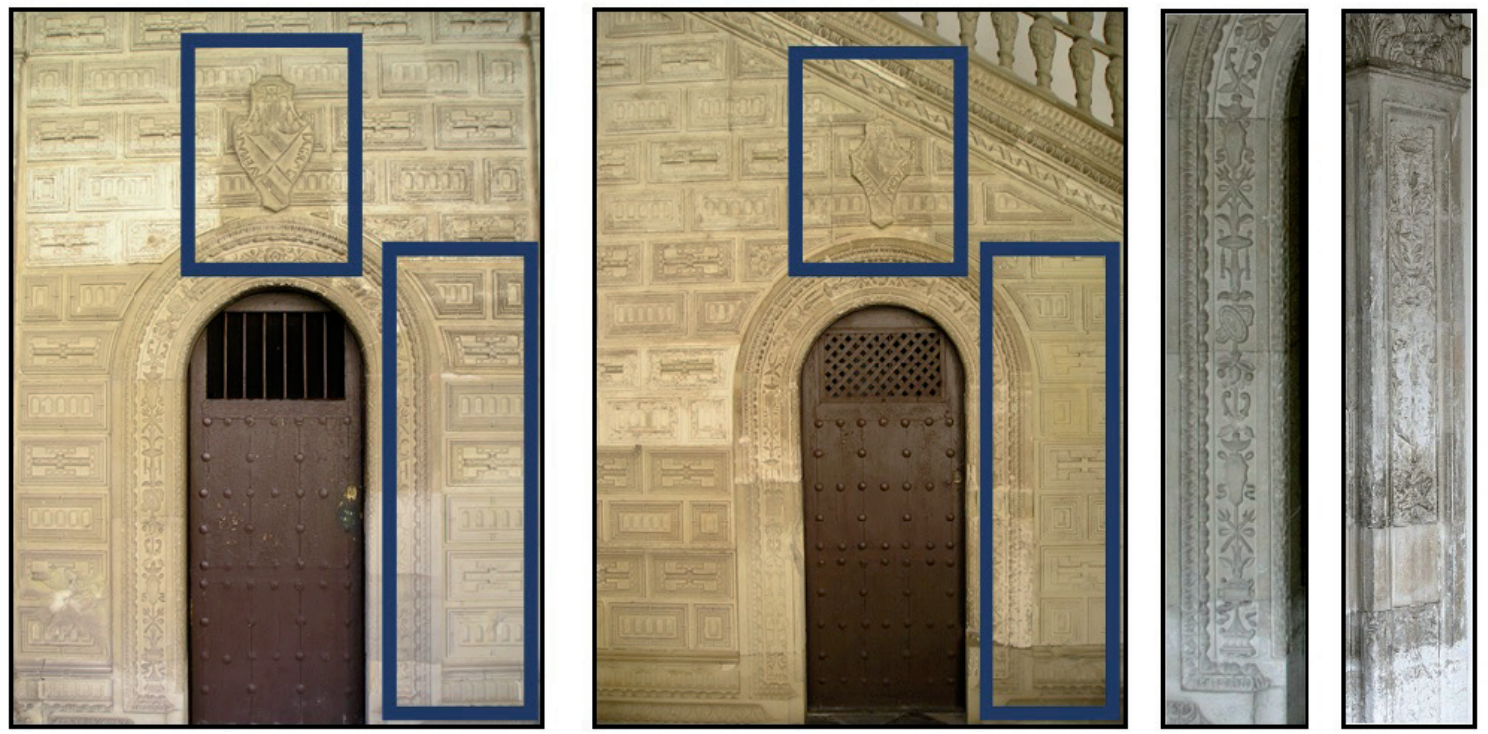

- Fig.8. Paramento de la escalera donde se aprecia el despiece de los sillares así como los motivos heráldicos y el cambio en la disposición a tresbolillo. Detalle comparativo de una de las jambas de la puerta izquierda con respecto a la decoración de la pilastra inferior derecha. Hospital de Santa Cruz, Toledo. Fotografías del autor.
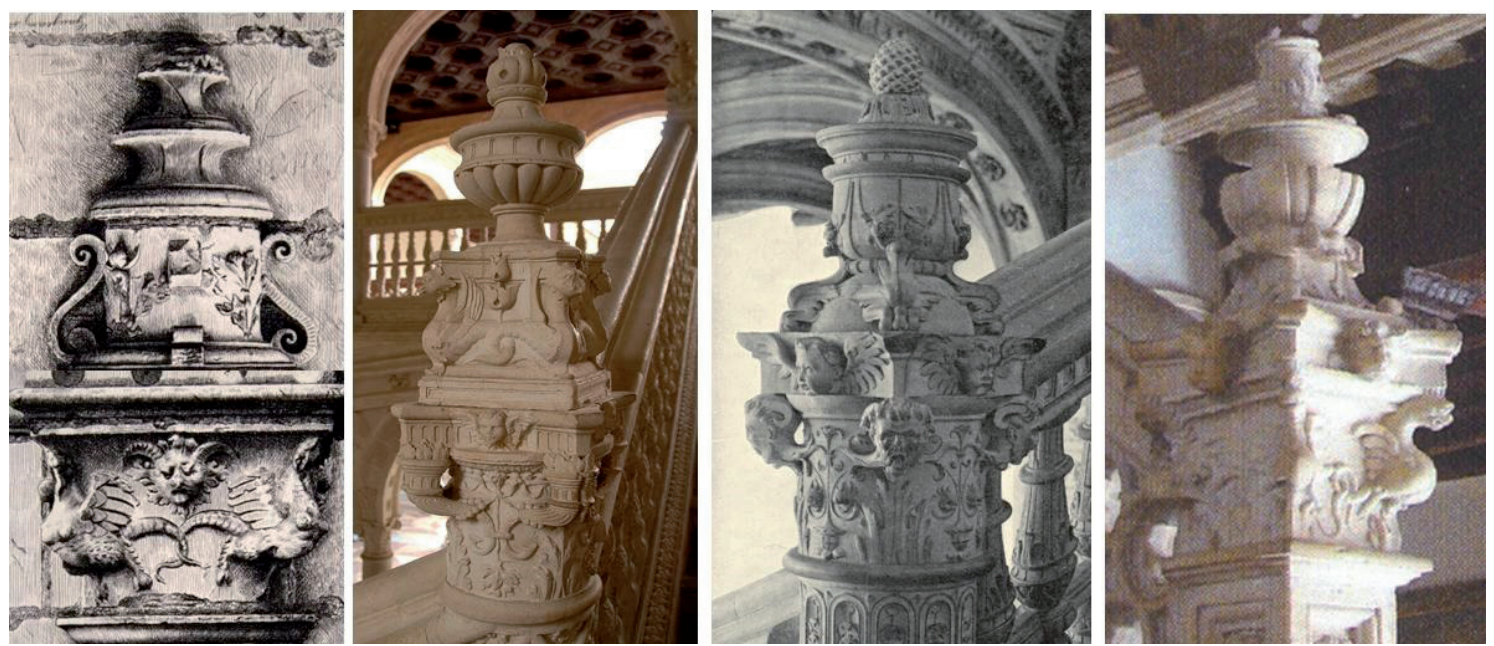

- Fig.9. Recomposición de una de las ménsulas exteriores del Castillo de Chambord y su comparativa con los montantes de las escaleras del Hospital de Santa Cruz en Toledo, el Palacio Arzobispal y el Convento de Carmelitas Descalzas de la Purísima Concepción o de la Imagen, en Alcalá de Henares. 


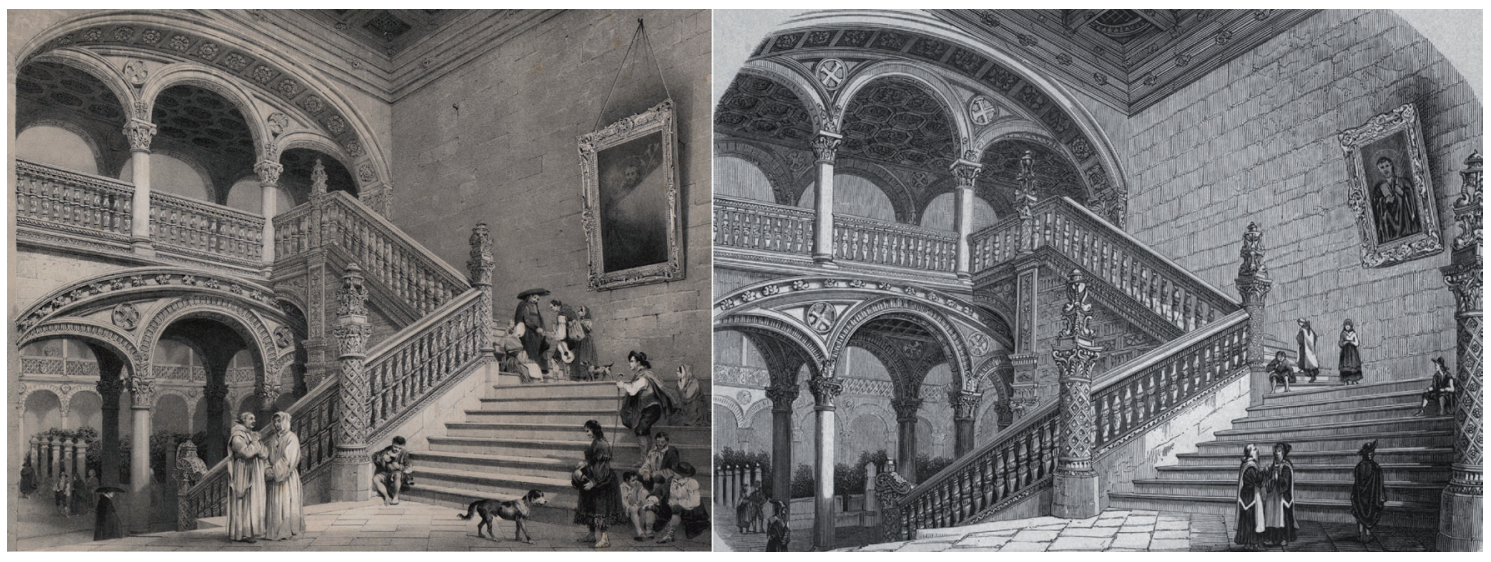

- Fig.10. Vista de la escalera del Hospital de Santa Cruz a mediados del siglo XIX en dos dibujos contemporáneos. G. PÉREZ DE VILLAAMIL, España artística y monumental, tomo I, cuaderno 8, estampa III, París, 1842. Versión de A. F. PANNEMAKER de hacia 1848.
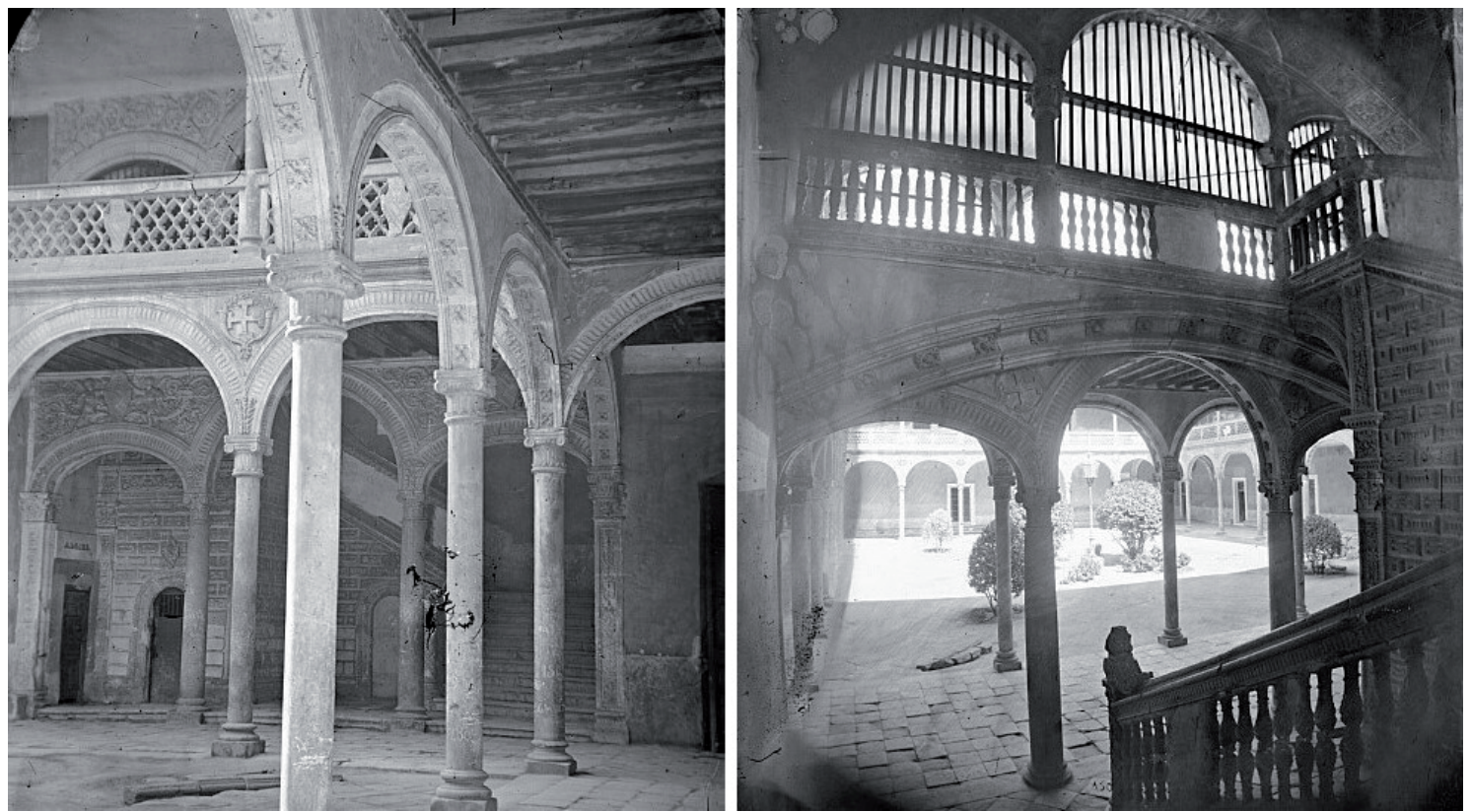

- Fig.11. Vistas de la embocadura e interior de la caja de la escalera del Hospital de Santa Cruz, donde se aprecia el estado de degradación en que se encontraba hacia 1880-1903. Archivo Municipal de Toledo. Colección Casiano Alguacil, CA-0516-VI y CA-0513-VI. 

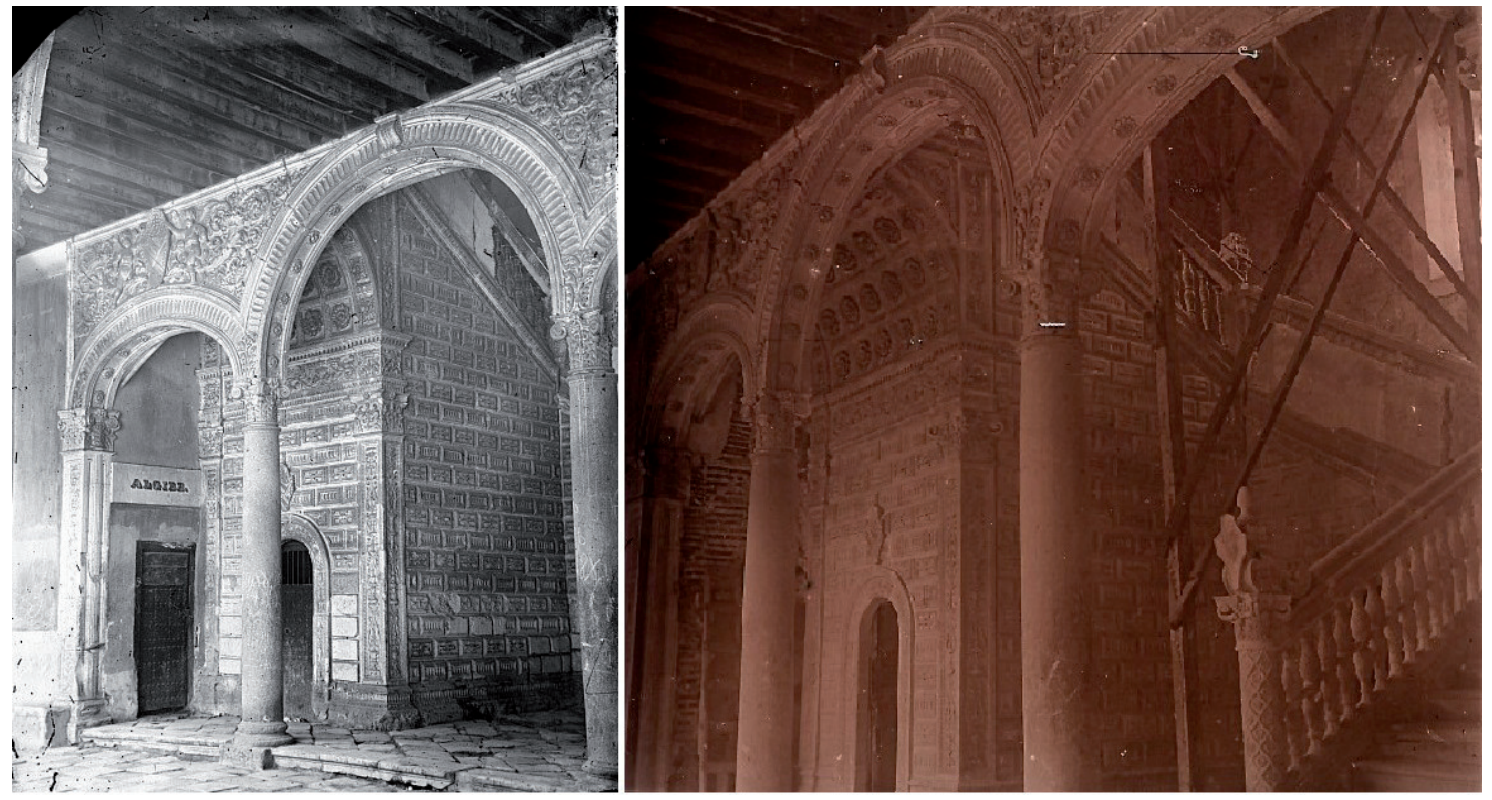

- Fig.12. Vista de la escalera del Hospital de Santa Cruz en 1880-1903 y hacia 1920, apuntalada e inmersa en pleno proceso restaurador. Archivo Municipal de Toledo. Colección Casiano Alguacil, CA-0514-VI y Fotografía de Ángel del Campo Cerdán.
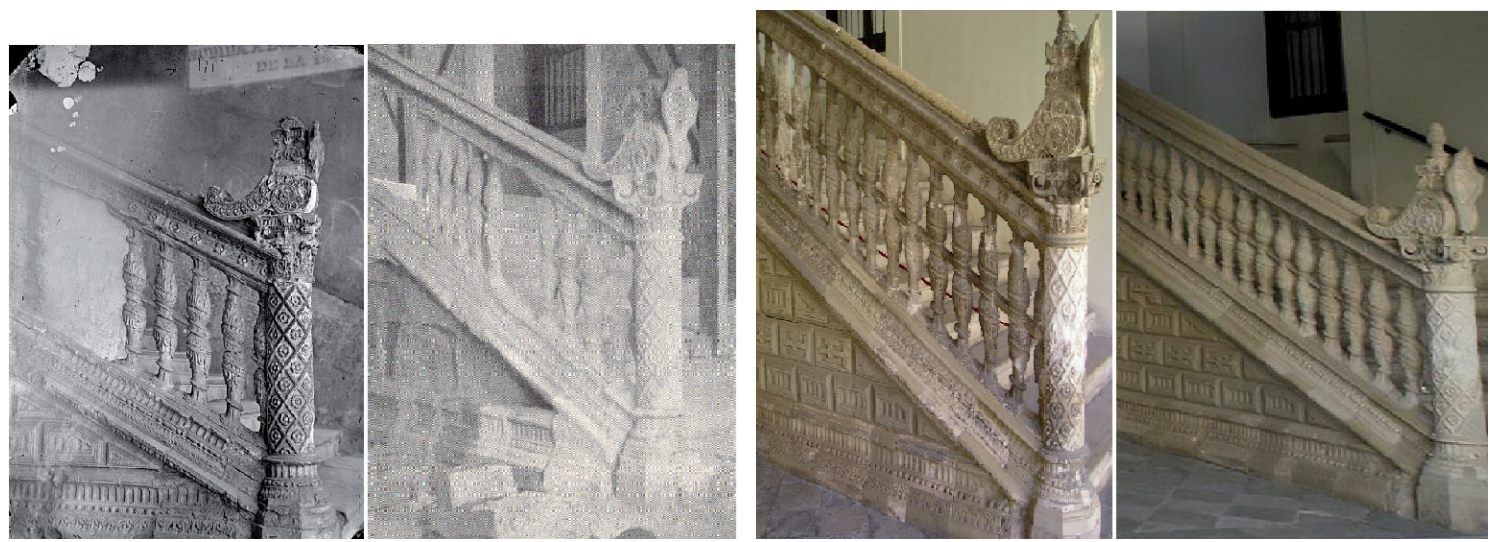

- Fig.13. Detalle comparativo de la balaustrada del primer tramo de la escalera hacia 1880-1903 donde se aprecian los recrecidos de cemento en la balaustrada, en 1920 durante una de sus primeras restauraciones en la que se sustituyen sillares del paramento junto al escudo del montante, en el año 2005 antes de la última intervención y finalmente en su estado actual en el año 2010. Madrid. Archivo Municipal de Toledo. Colección Casiano Alguacil, CA-0509-VI y A. WHITTLESEY, The renaissance architecture of central and northern Spain, Nueva York, 1920. 